\title{
Harnessing the Demographic Dividend: Opportunities and Challenges for Bangladesh
}

\author{
Md. Jalal Uddin ${ }^{1}$, Mst. RezwanaKarim ${ }^{2}$
}

\begin{abstract}
The demographic dividend refers to the potential economic benefit offered by changes in the age structure of the population, when there is an increase in working-age population and an associated decline in the dependent age population. More people in the working age group and lower dependency ratio mean higher saving and investable surplus, leading to higher economic growth. The prime objective of this article is to explore how Bangladesh can be benefitted by the optimum utilization of demographic dividends; as well as the challenges Bangladesh might face if they remain unutilized. This paper gave main emphasis on secondary data. Demographic dividend is the window of opportunity that opens for a population only once. How much benefit Bangladesh will realize from this demographic dividend depends on employment opportunities in the economy. If there is little employment opportunities, a large part of the increased labor force will remain unemployed, hindering the benefit to be reaped from demographic dividend. Benefits of demographic dividend also depend on human resource development. Bangladesh has to concentrate on developing several policies for all levels of education including vocational education and training to create a skill workforce. If Bangladesh fails to grab this opportunity immediately, this young population could create a disastrous hazard for the nation.
\end{abstract}

Keywords:Demographic Dividend, Economic Growth, Human Capital, Rate of Employment, Vocational \& Educational Training.

\section{INTRODUCTION}

Demographic dividend is defined as the economic growth potential that can result from shifts in a population's age structure, mainly when the share of the working-age population is larger than the non-workingage share of the population (UNFPA). 66 percent of the population of Bangladeshis aged between 15 and 64 years, and belong to the workforce. By 2030, the population of this age group would rise to 70 percent, but then it will start declining, according to the UNDP's Asia Pacific Human Development Report launched in Dhaka on April 26, 2015.19 percent of the country's population is between 15 and 24 years, which hold immense potential, but the number will decline after 2030. The number of people aged above 60 years in the country is now 11 million, which would be 22 million in 2030 and 44 million in 2050. This means that Bangladesh needs to invest right now in the human capital of its young people if it wants to reap the benefits of a large demographic dividend. A failure to act on these issues could have a damaging effect on future prospects, as unemployment rises and rising numbers of old people begin to overwhelm available resources. Embracing and understanding demographic challenges must therefore be a priority for the government. According to the UNFPA report, despite the government's greater attention to them, the youths still confront many obstacles that keep them from safely transitioning into adulthood and the workforce. According to the Bangladesh Bureau of Statistics' latest report, only 6 lakh jobs were created in the last two years, whereas some 15-20 lakh new candidates prepare for the job market every year. So what happens to the young men and women who remain jobless? Some five lakh (mainly men) of them go abroad every year, mainly to the oil-rich Arab countries, or to Singapore and Malaysia. But how do they fare overseas? It is obvious to everyone that our youth has the ability to reach their potential if they are guided correctly. Unfortunately this is not often the case. Due to poverty many children cannot finish their high school; if they are girls they are married off and if boys they are sent to work. It is completely up to the government to ensure that these kids at least finish high school and enter a college or receive technical education at vocational schools by giving appropriate subsidies.

\subsection{Objective of The Research/study:}

The prime objective of the study is to explore how Bangladesh can be benefitted by the optimum utilization of demographic dividends as well as the challenges Bangladesh might face if they remain unutilized.

${ }^{1}$ Lecturer, Department of Business Administration, Northern University Bangladesh.

${ }^{2}$ Lecturer, Department of Law, Northern University Bangladesh. 


\subsection{Literature Review}

Bangladesh is going through the demographic transition, and is experiencing an once-in-a- lifetime. This outcome can be generalized in a variety of ways. One important possibility is by increasing investment in human capital. Increase in investment in physical capital should also be emphasized. For economic benefits to materialize there is a need for policies dealing with education, public health, and those that promote labor market flexibility and provide incentives for investment and savings. On the contrary, if appropriate policies are not formulated, the demographic dividend might, in fact, be a cost, leading to unemployment and an unbearable strain on education, health, and old age security (Dr. Khan A. Matin, 2012). Bangladesh should reap the benefits of a "demographic dividend," as the relative share of the working-age population increases. Whether Bangladesh can benefit from this dividend will depend on the quality of its human capital. Without a skilled labor force, Bangladesh's demographics could turn into a liability rather than an asset (Sabet\&Tazreen, 2013 ). Demographic dividends are not automatic. To realize the dividends, we will need educated, healthy and productive labor force. Only new and enhanced infrastructure will provide jobs, increase attractiveness for foreign direct investment, improve productivity and urbanization, and ultimately, connect us to the global economic markets which we desperately needs to access. We need to adopt an expansionary economic policy so that we can increase production, productivity and consequent employment generation for future workforce through higher investment in above mentioned sectors. This massive number of young working people, if provided jobs, will definitely generate economic activity. On the other hand, they can become a threat to stability and turn into 'demographic burden,' if we were unable to provide them work or business. (The Independent, 2014). In order for vocational training to be successful, the successes achieved through labor market, a knowledge-based economy, the struggle against social inequality as well as the awareness of a combined and highly qualified vocational framework is required. Having all those things present to some extent in Bangladesh, the country has been suffering from lack of skilled manpower due to the poor formulation and implementation of strategies. If Bangladesh wants to achieve competitive advantage through its large workforce then there is no alternative to transform manpower into human resource by the proper implementation of vocational education and training (Newaz, Faruquee, Farha, 2013).Galor and Weil (2000) characterize the demographic transition as going through stages. Before the transition, population growth has a negative impact on economic growth.

The changing age structure favors savings, higher female labor force participation, and lower fertility rates (Bloom et al., 2009; Soares\&Falcao, 2008). Additionally, with declines in child mortality, children come to be seen as "consumption" rather than "investment", and parents prefer fewer children, but place greater emphasis on the quality of education and health. This increases productivity (Rosenzweig, 1990; Soares, 2005). Another strand of the literature characterizes demographic transitions as a window of opportunity to earn a demographic dividend (Carvalho and Wong, 1999; Pool, 2007), if good policies are in place (Bloom and Canning, 2000). Without proper policies, the increase in working age share may lead to rising unemployment and fuel economic and social risks (Bloom et al., 2003, 2007; Lorentzen et al., 2008). Some of the main policy variables considered in the literature include the quality of governmental institutions, labor market regulation, and macroeconomic management, openness to trade and capital flows, and human capital. Efficiently channeling the savings from the demographic transition and preparing for an aging population by making good use of pension assets can also contribute to economic growth. From the above study it is clear that demographic dividend is a very important issue in Bangladesh right now. The existing studies on this matter are not appropriately highlighting the opportunities and challenges of this issue. So it is believed this paper will not only identify the problems and prospects regarding the topic but also give possible solutions.

\section{METHODOLOGY}

This study focused on qualitative method. The study inputs were collected data and information from both primary and secondary sources. The primary data were collected from direct observation on population and personal interaction with various age groups. The secondary sources of data include publications by various authors on demographic issues, newspaper articles based on demographic dividend, reports of government and non-government agencies.

\section{ANALYSIS AND FINDINGS}

\subsection{Scenario of demographic dividend in Bangladesh}

The countries in South Asia would acquire a demographic dividend for a period of an average of 50 years. Among the countries, on an average, Bangladesh would acquire a highest dividend which is estimated at around 1 percent during the period of window of opportunity 1980- 2020(International Population Conference, 2009). 
Figure 1: Estimated first demographic dividend in Bangladesh

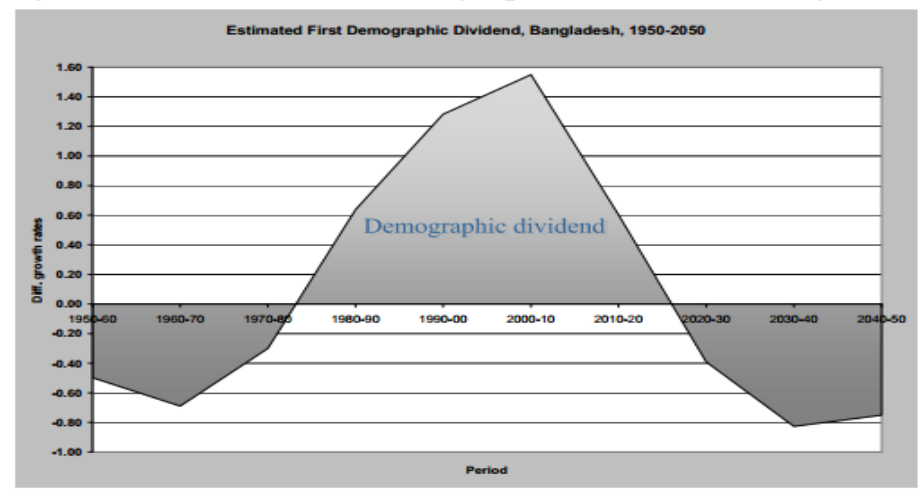

Source: Record from International Population Conference, 2009

Latter half of the 20th century, most working age Bangladeshis had to invest their time and income in taking care of a large number of children. These children have since grown up and are contributing to the economy, but they have had far fewer of their own children than their parents" generation. As shown in Table 1, the result is more working age Bangladeshis with fewer dependents to care for. In 1961, approximately 48.8\% of the population had to care for $51.2 \%$ of the population. By 2012, however, an estimated $61.6 \%$ percent of the population had to care for only $38.4 \%$, freeing up both time and income.

Table 1: Demographic changes in Bangladesh.

\begin{tabular}{|l|l|l|l|}
\hline \multicolumn{4}{|l|}{ Demographic changes in Bangladesh } \\
\hline & $0-14$ yrs & $15-59$ yrs & $60+$ yrs \\
\hline 1961 & 46.0 & 48.8 & 5.2 \\
\hline 1974 & 48.0 & 46.3 & 5.7 \\
\hline 1981 & 46.7 & 47.8 & 5.5 \\
\hline 1991 & 45.1 & 49.5 & 5.4 \\
\hline 2001 & 39.4 & 54.9 & 5.7 \\
\hline 2012 & 33.6 & 61.6 & $4.8^{*}$ \\
\hline
\end{tabular}

Source: BBS, 2012

\subsection{Opportunities of demographic dividend}

The „demographic dividend"e leads to opportunities for growth in output per capita in two principal ways. One, there is an age-structure impact on total GDP due to increasing proportion of working-age group in total population and two is increasing the ratio of producers to consumers. Demographic dividend also increases labor supply, savings, human capital and domestic demand.

\subsubsection{Labor Supply}

Demographic transition passes through a phase when it adds to the labor force in two ways. One, the number of people in the working-ages gets bigger, and two, women are more likely to enter the labor market as fertility level declines. However, it depends on the ability of the market and workers to make able use of this scenario.

\subsubsection{Savings}

Lifecycle variations in productivity lead individuals to vary their savings over their lifetime in order to accommodate their consumption. Demographic transition thus encourages savings which in turn can boost country's ability for investment and growth.

\subsubsection{Human Capital}

It is premised that demographic transition has significant effect on investment in human capital. Increasing life expectancy makes parents invest more in their children's human capital as the premium of higher education increases and lasts longer. As a consequence, the labor force becomes more productive, gets higher wages and there is improvement in the standard of living.

With shrinking of young population pressure on the education system is reduced, which can help countries to invest more in improving the quality of education and in higher levels, rather than in making investment in basic education. It cannot be emphasized enough that it is not the quantity but the quality of education that is more important for human capital formation and economic growth.

DOI: 10.9790/0837-2108080813 $\quad$ www.iosrjournals.org $\quad 10 \mid$ Page




\subsubsection{Increase in domestic demand}

Not only savings but also per capita income is rising and dependency ratio is decreasing. As a result domestic demand is also increasing.

\subsection{Challenges of demographic dividend}

However the opportunity and the reality are not synonymous. How much benefit Bangladesh will realize from this demographic dividend depends, among others, on the employment opportunities in the economy. If there is little employment opportunities, a large part of the increased labor force will remain unemployed, hindering the benefit to be reaped from demographic dividend.

Figure 2: Trend in unemployment

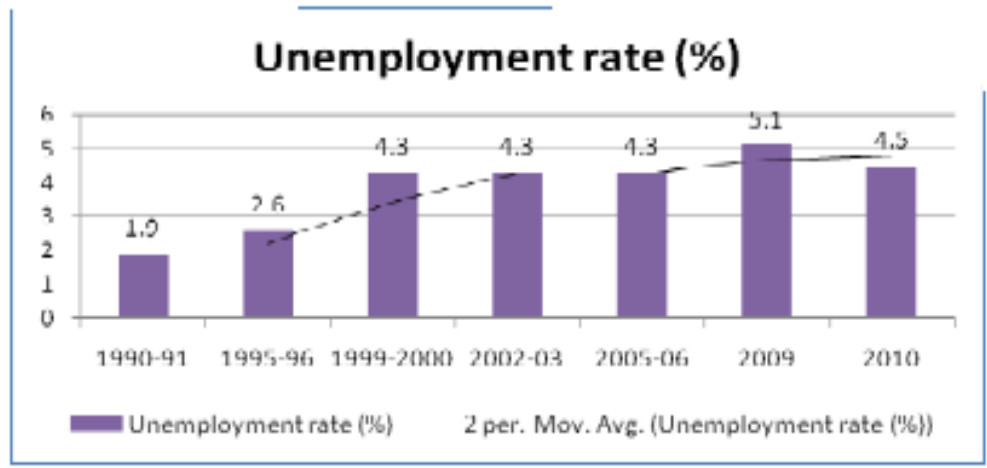

Source: Bangladesh economic review, 2010 and BBS

According to The Asian Development Bank (ADB), Bangladesh is expected to have 78 million workers by 2025 , up from 56.7 million in 2010, of whom two thirds have only minimal education and $4 \%$ have received any kind of training. There are few people in the labor market with technical/vocational qualifications; the 2002-03 Labor Force Survey estimated only 53,000 such men and 5,000 such women.

Now in Bangladesh there are overall 121 government institutes and 1,473 private institutes for vocational education and training (International Journal of research studies in education 2013). Bangladesh may suffer a bit from aging problem by the year 2050, slightly losing the demographic dividend of having more young population, suggests a UN report. By the middle of the current century, the country's population of over 60 years of age will rise three times -- 21 per cent of the aggregate population, said the report published by the UN's department of economic and social affairs.

Figure 3: Percentage of elderly population in Bangladesh

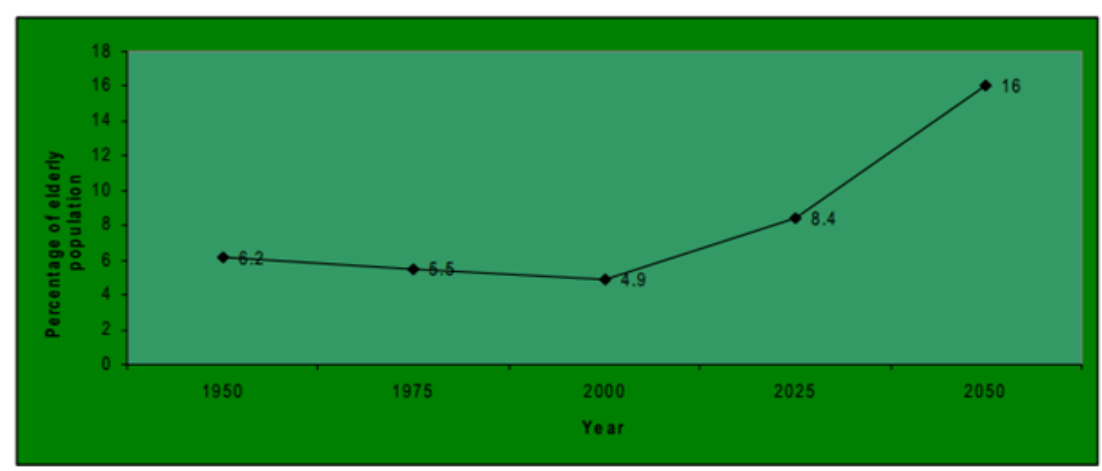

Source: World Population Prospect 2009

Percentage of older persons among total population indicates the pace of ageing. It is an indicator on the basis of which it is possible to say at what pace ageing is taking place and its intensity. The percentage of the elderly population is increasing with the advancement of time. The percentage of the elderly population in 2050 might be about three times higher than the percentage in 2000. The key point here is that the elderly population keeps growing and will continue to grow. 


\subsection{Findings of the study}

- Demographic dividend helps improve living standards of the population through increased:(i) Capital formulation,(ii) Savings and investment, (iii) Female participation in labor force,(iv) Improved quality of labor force,(v)Increased demand of goods \& services

- Demographic dividend enhances economic growth. We are now passing the optimum period for investing in human resources and establishing other enabling conditions for economic growth in Bangladesh.

- Like in many developing countries, the official statistics on the unemployment rate is quite low (4.5\%); however it conceals the considerable under- employment which is of greater concern.

- If the economy of our country cannot significantly enhance its employment generating capacity, the ranks of unemployed and underemployed will soon reach alarming levels.

- There are few people in the labor market with technical/vocational qualifications.

- Benefits of demographic dividend depend on human resource development.

- The demographic dividend is time-limited. Many developed nations are facing the end of their demographic transition, and now must plan for their aging populations and a decline in their ratio of workers to dependents.

- The existing working-age population of Bangladesh will transform into the elderly population within the next one decade or so.

- Social protection for the old or retired personnel is practically inoperative in most of the cases except those of the government, public sector bodies or a few private corporate houses.

- There is a strong need for funding pension and other retirement funds, involving the insurance companies in Bangladesh, for employees in government, public and private sector agencies.

\section{CONCLUSION\& RECOMMENDATIONS}

Age structural transition will give an opportunity and policy maker should take advantage of it to reformulate their social and economic policies. In order to meet the challenges in the future, it is important to exploit the window of opportunity available for a relatively short period, a one-time gift from demographic transition with appropriate economic and social policies. Developing human resources is a must to utilize the benefits offered by demographic dividend.

- To ensure the maximum utilization of the Human resources, capital investment in infrastructure, improved technology, manufacturing plant, market liberalization, etc are essentials.

- Major policy thrust required for ensuring proper role of young people in the socio- economic development of the country.

- Rising employment opportunity and more productive and more remunerative employment creation is required.

- Creating environment for external investment so that more job will be created in different sector.

- Creation of young entrepreneurs can be an important route to youth employment generation. Emergence of young entrepreneurs can also act as a stimulus for economic growth and this strategy is receiving attention worldwide.

- The Vocational education and training system should be flexible and adapt to market needs. Newly emerging sectors should be identified and emphasis should be given to these sectors.

- General business skills and management training for all VET graduates is very important. Because they lack these skills, most employed graduates fail to get promoted. This further discourages better students from entering the VET system.

- More attention needs to be paid at all levels of education to improving critical thinking and problem solving skills and to raising English abilities to university standards.

- The already adult and not-yet-skilled cohort of workers needs to be absorbed into the economy through expanded opportunities in labor-intensive sector.

- To prevent diminution of the demographic dividend potential by the present youth bulge, this generation and those that follow it should be encouraged and enabled to finance their consumption needs in old age. These may take the form of creating or expanding private pension plans or modifying tax treatment of income to incentivize savings.

- To capitalize on the demographic dividend we need to create a growth-conducive environment through economic policies, like free trade, diversification of trade policies, investment in infrastructure, etc.

- To integrate new workers in the economy through labor policy we have to ensure that new jobs are progressively created in more knowledge-intensive sectors with greater added value as the educational quality of the population increases.

- To prolong the demographic dividend through economic policies we need to reinforce policies to promote private savings among the aging working population to finance their retirement. 
- Also through employment policies we can lengthen the working age to prolong the demographic dividend.

- Making the best out of the current demographic dividend that Bangladesh enjoys is vitally important so that it can take timely steps for operating a funded pension system that will take care of the elderly. Once the demographics change, an ageing population scenario will emerge that requires huge resources to look after the needs of the elderly.

\section{REFERENCES}

[1] Drummond, Paulo.,Thakoor, Vimal., and Yu, Shu. (2014).Africa rising: Harnessing the demographic dividend. IMF working paper, African department.

[2] Dilruba, Sakina\&Alam, Onysa (2016).Demographic dividend in Bangladesh: Opportunities and challenges, Asian Journal of Multidisciplinary Studies. Vol.4, Issue 4, 108-113.

[3] Geoffrey Hayes. \& Gavin Jones (January-2015). The Impact of the Demographic Transition on Socioeconomic Development in Bangladesh: Future prospects and Implications for Public Policy. A background paper prepared for the Bangladesh planning commission of the general economics division in support of the development of the 7th five-year plan 2016-2020.

[4] Haider, Abu Afsarul. (June 17, 2014). Demographic dividend could turn into demographic burden, The Independent.

[5] Haider, Abu Afsarul. (April 21, 2015). Demographic dividend: A big challenge. The Financial Express.

[6] Matin, Khan A. (2012).The Demographic Dividend in Bangladesh: An Illustrative Study, Dhaka, Bangladesh: 18th Biennial Conference of the Bangladesh Economic Association.

[7] Navaneetham, K. \&Dharmalingam, A. (2009).Age Structural Transitions, Demographic Dividend and Millenium Development Goals in South Asia: Opportunities and Challenges. Morocco: International Population Conference.

[8] Palma, Porimol (May 21, 2016). Getting the best out of a youthful nation. The Daily Star.

[9] Sabet, Daniel M. \&Tazreen, Afsana. (2013). Human capital: The missing link for future economic growth.University of Liberal Arts Bangladesh.

[10] Shohag, Abdullah Al Mahmud. (21 Apr, 2015). Demographic dividend: Reality and possibility for Bangladesh. The Independent.

[11] The World Bank. (November 2006). The Bangladesh Vocational Education and Training System: An assessment. Dhaka, Bangladesh. 